\title{
Word recognition as a function of spelling direction during study and test*
}

\author{
GREG CERMAK, JOHN SCHNORR, and HERMAN BUSCHKE \\ Stanford University, Stanford, Calif. 94305
}

The spelling direction (backward or forward) of words presented for study and test was varied factorially. During recognition Ss indicated which word of each test pair had been presented for study, and the incorrect choice of each pair was a homophone, a synonym, or a word unrelated to the correct choice. Recognition was worst with synonym distractors and best with unrelated word distractors. For each type of distractor, recognition was better for backward-spelled study words than for forward-spelled study words, and words spelled in the same direction in both study and test were recognized better than words spelled in a different direction during study and test. The latter result supports the hypothesis that visual information may be important for word recognition. The latencies of correct recognition responses suggested that memory of decoding acts can facilitate subsequent similar decodings.

Research evidence suggests that words are represented in long-term memory as composites of semantic, associative, and phonetic information (e.g., Anisfeld \& Knapp, 1968). Recognition in a two-alternative forced-choice test is better if the distractor (i.e., incorrect choice) is unrelated to the target word (i.e., the word previously presented for study) than if the distractor is an associate, synonym, or homophone of the target (Underwood \& Freund, 1968; Buschke \& Lenon, 1969; Cermak, Schnorr, Buschke, \& Atkinson, 1970). Recognition performance in these experiments was generally very good regardless of the relationship between the target word and its distractor. Since long-term memory is often concluded to be primarily semantic (e.g., Adams, 1967), the high recognition rates obtained when the distractor was a synonym of the target suggests that information other than semantic, acoustic, or associative word properties may be important for word recognition.

Wallach \& Averbach (1955) tested recognition memory for nonsense words and obtained results which they interpreted as evidence for a visual component of recognition memory. The value of the graphic information inherent

*This investigation was supported by USPHS Research Grant MH-08556 and USPHS Research Scientist Award K3-MH-23,796 to Herman Buschke from the National Institute of Mental Health. Herman Buschke is now at the Saul $R$. Korey Department of Neurology, Albert Einstein College of Medicine, Bronx, New York 10461. During the period of this research, the first author held NIH Research Fellowship 1-F01-MH-45514-01, and the second author was US PHS Postdoctoral Fellow 1-F02-HD-29,231-01. in printed study words for later recognition is unknown, but it is thought that such information must be available in some form in long-term memory (e.g., Norman, 1969 , p. 136). Perhaps visual information is of sufficient value to establish a high base rate of recognition, so that distractors which are similar to the target in other respects can produce only relatively small confusion effects. The purpose of the present experiment was to test this hypothesis by varying the spelling direction (backward or forward) of the words presented during study and test. If visual information is valuable for word recognition, performance should be better if the physical appearance of the test word is the same as it was in study rather than if the test word is spelled differently in study and test. If visual information is of no value for recognition, performance should not differ for these two cases.

\section{SUBJECTS}

Sixteen male and seven female introductory psychology students at Stanford University participated as a course requirement.

\section{MATERIALS}

The stimuli were 594 English words of all parts of speech, with Thorndike-Lorge (1944) frequencies of 1-100 per million. The words formed 99 homophone pairs, 99 synonym pairs, and 99 pairs of words unrelated in sound, meaning, or association.

\section{PROCEDURE}

$S$ was seated at a Teletype connected to a PDP-1 computer. An average of three Ss participated in a session. Instruction, presented by tape recorder, stressed covert pronunciation of each word and concentration on word meaning during study. Ss were told they would later be exposed to a two-alternative forced-choice recognition task in which the test words would be spelled either in a forward or a backward direction. $S$ then studied, at his own pace, a list of 216 words which appeared on the Teletype so that only one word was visible at a time. Half of the words were spelled forward and the other half were spelled backward. A cross marking the true beginning of each word (e.g., +pious or suoipt) served as a cue to the spelling direction of each word. List composition was performed by programs controlling the PDP-1 so that a unique list of words was presented to each S. For each S, 72 of the 99 word pairs of each type (homophones, synonyms, unrelated words) were selected randomly, and one word of each pair was chosen unsystematically for presentation in the study list. Word-pair type and spelling direction were randomized over presentation order during study.

A two-alternative forced-choice recognition test on 198 word pairs (66 of the 72 presented for study for each word-pair type) immediately followed study. $\mathrm{S}$ selected the word of each test pair he thought had appeared during study by depressing the appropriate response key on the Teletype. Half of the words were spelled backward and the other half forward, although both words of each test pair were spelled in the same direction. Word-pair type and the spelling direction of the words were randomized over the sequence of test trials. The recognition test was self-paced, and response latencies were obtained on each trial.

By the end of testing, homophone pairs, synonym pairs, and unrelated word pairs were each distributed approximately

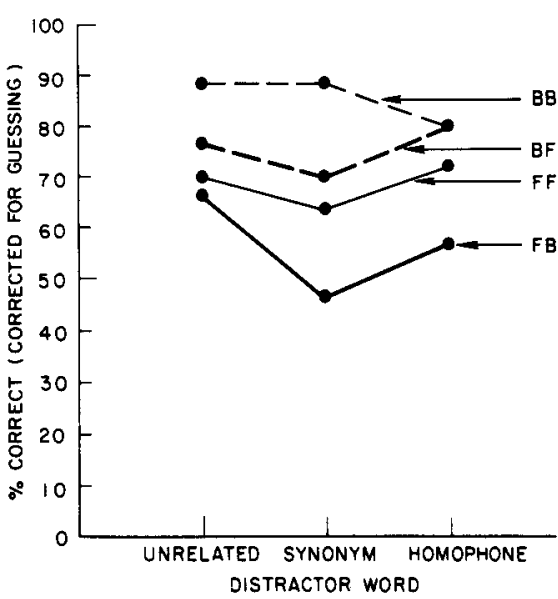

Fig. 1. Percent correct recognitions for three distractor types and four combinations of spelling direction during study and test. 


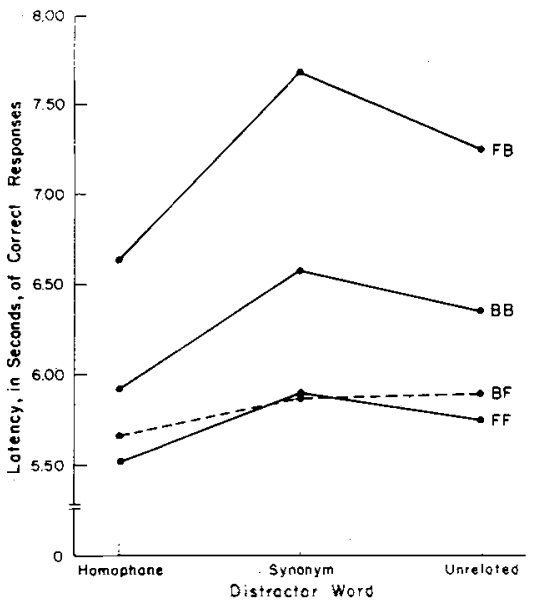

Fig. 2. Latency, in seconds, of correct responses for three distractor types and four combinations of spelling direction during study and test.

equally among four conditions: words spelled forward in both study and test (FF words); words spelled forward during study and backward in test (FB words); and, similarly, BF and BB words.

\section{RESULTS AND DISCUSSION}

Figure 1 presents the recognition probabilities, adjusted for guessing, for the three distractor types and each combination of spelling direction during study and spelling direction in test. 1 Figure 2 shows the latency of correct recognition responses for all experimental conditions.

The type-of-distractor effect on proportion correct $[F(2,44)=4.93$, $\mathrm{p}<.025]$ is consistent with previous findings. Recognition was greatest when the distractor was unrelated to the target; synonym distractors were more deleterious to recognition than were homophones; and all performance levels were quite high. The type-of-distractor effects on the latency of correct recognition responses $[F(2,44)=11.02, p<.001]$ did not quite follow this pattern in that correct responses were slowest on synonym pairs and fastest on homophone pairs. However, this result may have been an artifact of word length. 2

A result not anticipated was that words spelled backward in study were better recognized than forward-spelled study words $[F(1,22)=40.86, p<.001]$. Since mean exposure time during study was longer for backward-spelled words $\left(4 \frac{1}{4} \mathrm{sec}\right)$ than for forward-spelled words $\left(2^{1 / 2} \mathrm{sec}\right)$ $[t(12)=2.80, \quad p<.05],{ }^{3}$ one possible explanation is that $S s$ simply attended more carefully to backward-spelled words during study. An alternative explanation incorporates the notions of contextual association (McGovern, 1964) and extraexperimental sources of interference (Underwood \& Postman, 1960). Assume that associations are formed between the study words and the experimental context, with recognition depending, to some extent, upon the recovery of these associations during test. Backward-spelled words, being relatively novel, should have fewer preexperimental contextual associations than forward-spelled words. If the amount of interference in forming new associations is directly related to the number of existing associations, the probability that a context-study word association will be formed is lower for forward-spelled than for backward-spelled words. Recognition performance would therefore be better for the latter, since a greater number of context-study word associations would be available for recovery during test.

Words spelled in the same direction in both study and test were better recognized than words spelled differently in study and test, resulting in an interaction between spelling direction during study and spelling direction in test $[F(1,22)=18.37$, $\mathrm{p}<.001]$. Differently stated, recognition was better if the target had the same physical appearance in test that it had in study, which is consistent with the Wallach \& Averbach (1955) hypothesis that visual information may be important for recognition. One strategy that $S$ might have used in recognition is to compare the physical appearance of a test word with the memorial representation of the visual form of a study word, with response selection occurring whenever a match resulted. A second interpretation of the interaction effect is possible if it is assumed that (1) forward-spelled words were never misread; (2) some of the backward-spelled words were incorrectly decoded; (3) Ss were consistent in their decoding of backward-spelled words. With these assumptions, words in the $\mathrm{BB}$ and $\mathrm{FF}$ conditions would have the same decoding in both study and test. For the BF and FB conditions, however, incorrectly decoded backward-spelled words would not match their forward-spelled versions, and hence there would be no basis for true recognition. However, since the present study employed a self-paced procedure during both study and test, the assumption that an appreciable number of backward-spelled words were incorrectly decoded may be unwarranted.

The latency data also exhibited effects of spelling direction during study $[F(1,22)=24.10, \quad \mathrm{p}<.001], \quad$ spelling direction during test $[\mathrm{F}(1,22)=26.20$, $\mathrm{p}<.001]$, and an interaction between these two variables $[F(1,22)=12.79$, $p<.001]$. Figure 2 shows that for correct recognition responses, backward-spelled test words were more slowly responded to than forward-spelled test words, as expected, since the former must be decoded. In addition, forward-spelled test words were recognized in the same amount of time, regardless of their spelling direction during study. Third, backward-spelled test words were more quickly responded to if they had been spelled backward in study rather than forward. This result is consistent with the hypothesis that Ss can remember decoding acts which serve to facilitate later decodings of a similar nature (e.g., Neisser, 1967), since the correct choice of a BB test pair already had been decoded during study, whereas the correct choice of an FB test pair had to be decoded for the first time during the test session.

\section{REFERENCES}

ADAMS, J. A. Human memory. New York: McGraw-Hill, 1967.

ANISFELD, M., \& KNAPP, M. Association, synonymity, and directionality in false recognition. Journal of Experimental Psychology, 1968, 77, 171-179.

BUSCHKE, H., \& LENON, R. Encoding homophones and synonyms for verbal discrimination and recognition. Psychonomic Science, 1969, 14, 269-270.

CERMAK, G., SCHNORR, J., BUSCHKE, H., \& ATKINSON, R. C. Recognition memory as influenced by differential attention to semantic and acoustic properties of words. Psychonomic Science, 1970, 19, 79-81.

McGOVERN, J. B. Extinction of associations in four transfer paradigms. Psychological Monograph, 1964, 78, No. 16.

NEISSER, U. Cognitive psychology. New York: Appleton-Century-Crofts, 1967.

NORMAN, D. A. Memory and attention: $A n$ introduction to human information processing. New York: Wiley, 1969. P. 136.

THORNDIKE, E. L., \& LORGE, 1. The teacher's handbook of 30,000 words. New York: Bureau of Publications, Teachers College, Columbia University, 1944.

UNDERWOOD, B. J., \& FREUND, J. S. Errors in recognition learning and retention. Joumal of Experimental Psychology, 1968, 78, 55-63.

UNDERWOOD, B. J., \& POSTMAN, L. Extraexperimental sources of interference in forgetting. Psychological Review, 1960, 67, 73-95.

WALLACH, H., \& AVERBACH, E. On memory modalities. American Journal of Psychology, $1955,68,250-257$.

\section{NOTES}

1. The correction formula was a standard one: $[P(C)-g] /(1-g)$, where $P(C)$ is the observed proportion correct and $z$ is the probability of a correct response by guessing, 0.5 in this case.

2. Further analyses revealed that the word-type (and therefore word-length) effect on latency was solely attributable to the backward-spelled test words. Inspection of the words used in the experiment revealed that synonym pairs had a mean of 6.2 letters, homophones a mean of 4.5 letters, and unrelated words averaged 4.9 letters. Therefore, latency was directly related to word length, which is to be expected for backward-spelled words.

3. Study times were available for only $12 \mathrm{Ss}$. 